\title{
22 MACHINE AGENCY AS PERCEIVED AUTONOMY: AN ACTION PERSPECTIVE
}

\author{
Jeremy Rose \\ Manchester Metropolitan University \\ United Kingdom
}

\author{
Duane Truex III \\ Georgia State University \\ U.S.A.
}

\begin{abstract}
Recent theoretical debates in the literature have taken up the themes of social and technological determinism in the context of actor network theory and structuration theory. This paper explores (computerized) machine agency from an action-based perspective. How is it that information technologies affect our actions, how can we marshal this property, and what can we do about the results if we don't like them? In order to gain some purchase on these questions, we distinguish between two styles of analysis and between two social systems or networks. Cross-sectional analysis is distinguished from longitudinal analysis. The use system, which enmeshes social practice and IT in our everyday activities is distinguished from the development system, which is responsible for putting the IT in place, maintaining, and updating them. In the majority of workday situations, cross-sectional analysis of the use system leads to the appearance of material agency. However, longitudinal analysis of the development system tends to locate agency in the design decisions of the developers. These analytical distinctions lead to a new conceptualization of machine agency as perceived autonomy from the development system. Unlike previous accounts, this view is consistent
\end{abstract}


with both structuration theory and actor network theory. This allows continued access to these powerful analytical vehicles and enables the strong analysis that is the precursor to effective action.

\section{Introduction}

Some recent contributions to the IS literature involving actor network theory and structuration theory focus on the relationship between the social and the technical. The debate has sometimes been characterized as a bipolar one, with technological determinism set against social determinism(Jones 1999; Markus and Robey 1988). More recent contributions based on structuration theory emphasize the recursive interaction of the social and the technical; thus Orlikowski (1992) gives us a structurational model of technology in which the technical is both constituted by, and constitutive of, the social. Actor network theory posits associations of human and non-human components without artificial distinctions between the social and the technical. A difficulty that both these well-established bodies of theory share, in different ways, is the notion of material (nonhuman) agency.

The concept of agency has a number of different facets. It may encompass actions and the freedom to choose those actions; intentionality, will, and power; causality, consequences, and outcomes (which may be intended or unintended); and decision making. Actor network theory and structuration theory offer rather different accounts of agency (compared in Table 1). In structuration theory, agency is the ability of humans to "make a difference" or cause an effect (Giddens 1984). Giddens distances agency from intentionality (since unintended consequences may engender effects as well as intended ones) and links it instead with power as "transformative capacity." In the structurational cycle of structure and agency, agency is a particularly human phenomenon that non-humans cannot possess. How could material objects act in the context of their understanding of structure (memory traces) and in doing so re-enact that structure? Clearly this is not possible. In structuration theory, material objects are resources to be employed by human agents. However, the ability to constitute (cause an effect upon) the social, as theorized by Orlikowski, implies technical (non-human) agency: the effect caused by the technical is the constitution of the social. Structuration theory is unable to resolve the problem of how technical artifacts, such as computer systems, seem to engender profound consequences.

By contrast, a central tenet of actor network theory affords non-humans the same status as humans in a principle of generalized symmetry. In an actor network, technical artifacts may be actors in the same way that humans are. Latour (1991) writes forcefully of the "testimony of non-humans." Elsewhere he indicates that sets of actants" may behave like machines which have themselves characteristics of agency, volition, and autonomy.

\footnotetext{
${ }^{1}$ In Science in Action (1992), Latour defines an "actant" as "both people able to talk and things unable to talk have spokesmen. I propose to call whoever is and whatever is represented as actant.... introduced the word 'actant' earlier to describe what the spokesman represents. Behind the [texts, instrument, laboratory]... what we have is an array allowing new extreme constraints to be imposed on 'something.' This 'something' is progressively shaped by its re-actions to these conditions" (pp. 83-84; 89).
} 
Table 1. Agency in Structuration Theory and Actor Network Theory

\begin{tabular}{|c|c|c|}
\hline & \multicolumn{2}{|l|}{ Agency } \\
\hline $\begin{array}{l}\text { Oxford English } \\
\text { Dictionary: }\end{array}$ & \multicolumn{2}{|c|}{$\begin{array}{l}\text { "The means of action through which something is done." } \\
\text { Agent: } 1 . \text { Person who does something or who instigates } \\
\text { some action. } 2 \text {. One who acts on behalf of another. } 3 \text {. } \\
\text { Something that produces an effect or change. }\end{array}$} \\
\hline $\begin{array}{l}\text { Associated } \\
\text { concepts }\end{array}$ & Structuration theory & Actor network theory \\
\hline Focus of theory & $\begin{array}{l}\text { Reconciliation of structure } \\
\text { and agency }\end{array}$ & $\begin{array}{l}\text { Interplay of actants; the } \\
\text { building and maintaining of } \\
\text { the networks }\end{array}$ \\
\hline Agents & $\begin{array}{l}\text { By definition, human } \\
\text { actors; machine agency not } \\
\text { allowed }\end{array}$ & $\begin{array}{l}\text { Actors, actants-either } \\
\text { human or other; machine } \\
\text { agency inferred and co-equal }\end{array}$ \\
\hline Action & $\begin{array}{l}\text { Explicit and assumed of } \\
\text { humans who have freedom } \\
\text { to choose actions }\end{array}$ & $\begin{array}{l}\text { Explicit and required of } \\
\text { actors, inanimate objects and } \\
\text { machines still have (limited) } \\
\text { freedom to act }\end{array}$ \\
\hline Power & $\begin{array}{l}\text { Enabler of action- } \\
\text { machines are resources that } \\
\text { extend the power of humans }\end{array}$ & $\begin{array}{l}\text { Exhibited in networks-non- } \\
\text { humans also have power }\end{array}$ \\
\hline $\begin{array}{l}\text { Intentionality or } \\
\text { volition }\end{array}$ & $\begin{array}{l}\text { Associated with agency but } \\
\text { not required; human agency } \\
\text { can exist with or without } \\
\text { intention }\end{array}$ & $\begin{array}{l}\text { Explicit and required to } \\
\text { construct and maintain } \\
\text { networks, inferred of non- } \\
\text { human actors }\end{array}$ \\
\hline $\begin{array}{l}\text { Causality, effects, } \\
\text { consequences }\end{array}$ & $\begin{array}{l}\text { Intended and unintended } \\
\text { consequences of action, } \\
\text { transformative power, re- } \\
\text { enaction of structure }\end{array}$ & $\begin{array}{l}\text { Interessement, enrolment, } \\
\text { translation leading to } \\
\text { formation of associations, } \\
\text { black-boxing, irreversibility }\end{array}$ \\
\hline $\begin{array}{l}\text { Decision-making } \\
\text { capacity }\end{array}$ & Assumed of humans & $\begin{array}{l}\text { Assumed of humans; } \\
\text { ascribed to non-human actors }\end{array}$ \\
\hline Structure & $\begin{array}{l}\text { Network of rules and } \\
\text { context, wholly human } \\
\text { constructions; "memory } \\
\text { traces" explicitly not } \\
\text { technology (material } \\
\text { resources used by people). }\end{array}$ & $\begin{array}{l}\text { Associations, networks of } \\
\text { humans, non-humans, black } \\
\text { boxes }\end{array}$ \\
\hline Relationships & Interactions between people & Associations in network \\
\hline $\begin{array}{l}\text { Independence, self- } \\
\text { government }\end{array}$ & Human, societal & $\begin{array}{l}\text { Human and non-human, } \\
\text { network }\end{array}$ \\
\hline
\end{tabular}


The simplest means of transforming the juxtaposed set of allies into a whole that acts as one is to tie the assembled forces to one another, that is to build a machine. A machine... is first of all, a machination, a stratagem, a kind of cunning, where borrowed forces keep one another in check so that none can fly apart from that group....it is important to note that the skills required to go from a [tool] to a [machine] are symmetrical....Complicated negotiations have to go on so that provisional alliances do not fly apart. [Latour 1992, p. 129]

However, many commentators are unable to accept the proposition that material things should have the same powers of agency as humans (Walsham 1997). Moreover, Latour would probably regard social and technical as unhelpful modern conceptual distinctions: "We are never confronted with science, technology and society," he asserts, "but with a gamut of weaker and stronger associations" (Latour 1992). Some aspects of agency in structuration theory and actor network theory are compared in Table 1.

The comparison table demonstrates that structuration theory and actor network theory, although often lumped together, have different and quite incompatible accounts of agency and the relationship between the social and the technical. Nor are these accounts able adequately to resolve difficulties central to researching information systems in their social contexts.

In trying to solve this problem, Jones (1999) proposes a middle course. Inanimate objects should be allowed agency, but without the particularly human component of intentionality. He offers a "double mangle" model of social and technological interaction. The "mangle of practice" describes human agency"s efforts to adapt intransigent material agency to its own ends in an emergent process. In double mangling, according to Jones, human agents "channel material agency to shape the actions of other human agents," or "marshal material agency to direct the actions of other human agents" in a "double dance of agency." In IS, we must relate this to human actors building and using computers systems. In this paper, we seek to build upon this account of material agency and the relationship between the social and the technical. IS is an applied discipline and we are primarily interested in action; our interest in theory is that it helps to promote better actions. In exploring these issues, we seek to move the debate in the direction of explicit IS concerns (which require explanations not of material agency in general, but of computerized machine agency in particular) and toward action. Hence, the purpose of the paper is to build on previous accounts of machine agency (in the context of understanding the relationship between the social and the technical) and offer new conceptualizations that facilitate rich analysis as a precursor to action.

The paper is structured as follows. The next section of the paper develops an understanding of analysis as the key link between theory and action. This helps to identify weaknesses in the double mangle model as a vehicle for action. In order to develop better understandings of machine agency, we then make two sets of distinctions about analysis. The first distinction concerns the type, or style, of analysis; the second concerns the its object or focus. We first distinguish between cross-sectional analysis and longitudinal analysis styles, then between analysis of the social system (network) that develops a computer system and the one that exploits or uses it. The distinctions are brought together to provide a framework for the deconstruction of two examples. The 
first is the example used by Jones in his double mangle paper. The second takes the form of a thought experiment. Using this analysis, a new conceptualization of machine agency is developed, compatible with both structuration theory and actor network theory, leaving the would-be analyst/actor in a stronger position. Finally, consequences for practice are elicited.

\section{Theory and Action}

A simple framework for relating theory and action is given first (Figure 1). It is derived from Checkland and Scholes (1990). Neither theory nor practice (action) is grounded (i.e., demonstrable without relation to the other). Theory must, in the end, be based on practice, whereas practice cannot be carried out in isolation from theories of the world. Analysis links the two. Analysis (using theory) of a set of phenomena permits action: I take the world to be like that, therefore I will act like this. Often this movement of thought is conflated into common sense or instinct and its parts are not really discernible. Theory is derived from practice via analysis. Theoretical discussions can take part in isolation from practice, but theory ultimately is not sustainable if it cannot be shown to relate to practice. Thus theory is the emergent result of analyzing practice; practice the emergent result of analysis governed by theory. In our applied discipline, for the development and use of information systems, it is necessary not only to have wellinformed and defensible theory, but theory that enables rich analysis and thus purposeful action.

Theories that allow us, then, to proceed to sensible actions do so by improving our powers of analysis. If we can make more sense of situated local phenomena, because of the power of the theoretical constructs at our disposal, we have a better chance of choosing a sensible course of action to deal with them.

In assessing the usefulness of the double mangle model for practice, we need to evaluate its analytical power. Both structuration theory and actor network theory can help us to make better sense of empirical situations. Structuration theory is a well-elaborated set of related concepts with well-demonstrated ability to help analyze phenomena in the IS arena (Barley 1986; Brooks 1997; Jones and Nandhakumar 1993; Walsham 1993). Actor network theory also offers valuable insights into the IS domain (Latour 1996; Walsham 1997). However, the double mangle model, with its conditional acceptance of

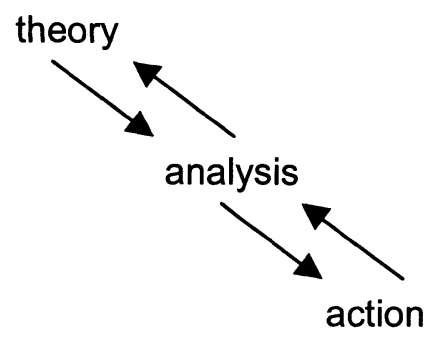

Figure 1. Theory and Action 
material agency, is not compatible with structuration theory. According to Giddens, the reflexive evolution of structure and agency is located in the minds of knowledgeable human actors, not embodied in artefacts. Artefacts are material resources which agents may employ (Jones 1997). Unfortunately, the double mangle model is not really compatible with actor network theory either. If only privileged human actors possess intentionality, then we must reassess whether the non-human actants can enrol, translate, interesse, delegate, inscribe - all actions seemingly requiring of intentionality. In adopting a compromise, a "blended middle" (Latour 1991), Jones (1999) constructs a tenable theoretical explanation. Unfortunately, the would-be analyst using Jones' model cannot employ the concepts of structuration theory or those of actor network theory with safety. These well developed bodies of theory become inaccessible. The double mangle model offers no similarly well articulated concepts to replace those which are undermined. Clearly the analytical power of the double mangle model is less well developed than that of structuration theory or actor network theory and the position of the analyst/practitioner is, therefore, weakened rather than strengthened. The implication is that we should search for understandings of machine agency that leverage the analytical power of the existing theory bases rather than diminish it.

\section{Distinction 1: Analysis Style-Cross-sectional Versus Longitudinal}

Analysis is central to the ability to take meaningful action. The theory behind meaningful action both enables rich analysis and is derived from it. However, there are many forms of analysis. In order to illustrate the effect that the choice of analysis may have on a given theoretical concept (in this case machine agency) or the interpretation of an empirical situation, a simple distinction between cross-sectional analysis and longitudinal (historical) analysis is made (Figure 2). The distinction is derived from Franz and Robey (1987) and is not intended to characterize exhaustively modes of analysis, but simply to enable the illustration of the effect of different kinds of analysis on theory and action. Cross-sectional (single period, point-in-time) analysis concentrates on the event or phenomenon at the expense of its history. A cross-section of a situation investigated at a single point in time reveals webs of related phenomena, or variables in particular states at the given moment. A systems analyst employing a traditional systems development methodology will largely concentrate on forming a picture of what is happening at the time of investigation. This may provide an in-depth analysis of a given situation, but it does so at the expense of forming a historical picture of why those phenomena are they way they are and not otherwise. In contrast, longitudinal analysis concentrates on understanding the evolution of a phenomenon over time. It may do so by taking smaller slices of the phenomenon's history, but over many points in time, or continuously. The amount and type of data captured and examined is an open issue. Some analysts may choose to concentrate on the web of exchanges, events, or relationships leading from development to development. Thus Latour's (1992, p. 104) study of the evolution of the Diesel engine traces its progress from source idea, through development, diffusion, and Diesel's suicide, to acceptance in the market place. 


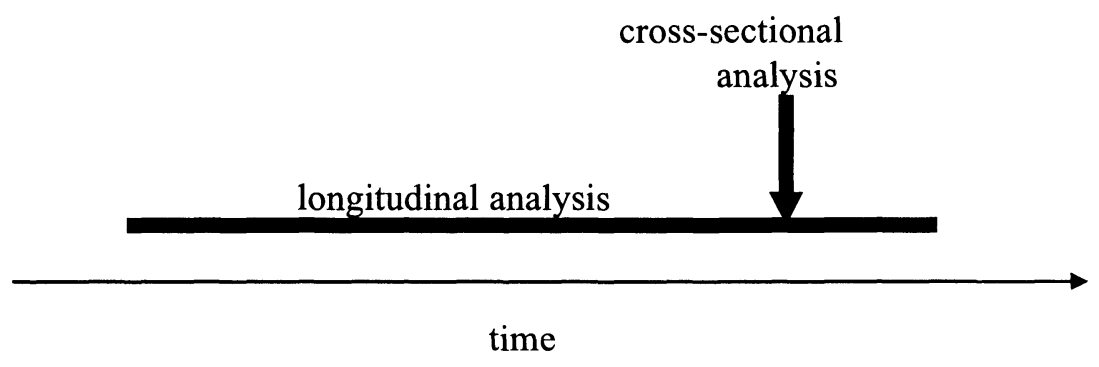

Figure 2. Longitudinal versus Cross-sectional Analysis

\section{Distinction 2: Analysis Focus-IT Use versus IT Development}

As the style of analysis may vary, so may the object, or focus, of enquiry. A common way of thinking separates the development of IT from its use (Figure 3). Machines may be analyzed in use, as human actors incorporate them into the task structures of their lives. Barley's (1986) study of computer tomography focuses on the use of the machine in its hospital environment. Machines may also be analyzed as they are developed (as in the Diesel engine example quoted above). Then "We study science in action and not ready made science or technology; to do so, we....arrive before the...machines are black boxed" (Latour 1992. pp. 258).

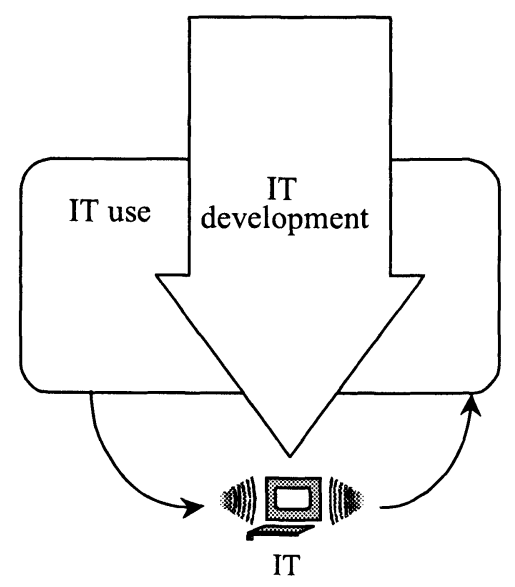

Figure 3. IT Use and Development 
Use and development cross over, overlap, and become enmeshed as developers investigate use for design purposes and as users provide feedback to developers or seek to influence development. Thus the distinction, while well established, is artificial (Jones and Nandhakumar 1993; Orlikowski and Robey 1991). In terms of structuration theory, we may think of a two social systems concerning use and development, which may be represented as sets of social practices, involving the recursive interaction of structure and action, routinized over time and space. Giddens does not theorize IT, but it must be embedded in the discourse that relates structure to action. Alternatively, in the context of actor network theory, we may think of use and development as networks. In the development network, the machine is the end product, whereas in the use network, it is a black-boxed component. The distinction between use and development is made here for analytical convenience; in practice, development and use are inextricably enmeshed.

\section{Analysis of Machine Agency}

Mapping the distinction between analysis styles on to the distinction between analysis foci gives a framework for the deconstruction of empirical examples (Table 2).

\section{Table 2. Framework for Deconstruction of Machine Agency Examples}

\begin{tabular}{|c|c|c|c|}
\hline & & \multicolumn{2}{|c|}{ Focus of Analysis } \\
\hline & & Use & Development \\
\hline \multirow{2}{*}{$\begin{array}{l}\text { Style of } \\
\text { Analysis }\end{array}$} & Longitudinal & & \\
\hline & Cross-sectional & & \\
\hline
\end{tabular}

Of particular importance to the deconstruction of these examples will be the difference in perspective on machine agency obtained by longitudinal analysis of the development system as compared with that obtained by cross-sectional analysis of the use system (represented by the shaded areas in the table). These perspectives provide a story line that guides our initial deconstructive reading of the examples to follow. Deconstruction, a technique for disassembling socially constructed meanings presented in texts, or phenomena represented as texts, is also an analysis technique used to decenter authorship of texts and to surface multiple, often inconsistent, readings. In the present instance, we choose a type of deconstruction that turns and contrasts a text while holding its meaning in a deferred or not quite complete state. This is similar to Derrida's (1992) notion of différance Hopper's (1987) linguistic "emergence" in that concepts kept "in play," repeatedly turned and reconsidered, may yield fresh insights and the surfacing and unfreezing of implicit assumptions. Our use of the deconstruction technique is similar to that of Beath and Orlikowski (1994). It is also consistent with the deconstruction 
techniques suggested by Boje and Dennehy (1994) and Truex, Baskerville, and Travis (forthcoming). We examine meta-narratives associated with both actor network theory and structuration theory and local narratives arising from the two cases chosen for illustration. Each meta-narrative and each case constitutes a text that is examined in the context of the set of concepts identified earlier. Deconstruction turns a step further as conclusions and constructs are held in abeyance while core analytical concepts (agency vs. autonomy) are themselves considered more deeply. Ideas arising from the suspension of closure eventually suggest a path through the knotty issues raised by Jones' double mangle model.

\subsection{Deconstruction 1: Jones' Lotus Notes Application}

Jones (1999) gives the example of a Lotus Notes application that was judged, by some of its users, to be unacceptably slow. He asks,

Are there inherent characteristics of technology, such as "speed" which inevitably lead to certain conclusions? Or are these apparent characteristics simply the playing out of broader social forces, reflecting, for example, decisions made in particular configurations of organizational power relations?

If we take a cross-sectional analysis of the use system for the Lotus Notes application at the point in time that it is implemented (which is more or less Jones' analysis), the speed of the application may appear a property of the technology. This property will have an outcome: it makes the application easy or difficult to use. Thus the variables "speed" and "user satisfaction" seem linked together. Users, as Jones hints, may socially construct their criteria for satisfaction. The application is a black box, apparently finished, outside the user's considerations. It is a fait accompli, sitting on the users' desks, and operates in a way that causes more, or less, satisfaction. In this analysis, the Lotus Notes application has a kind of agency: it makes a difference or causes an effect. If we focus on the use system while performing cross-sectional analysis, what tends to emerge is strong machine agency. At a given point in time, and with criteria set by users' expectations, the Lotus Notes application exhibits a property, speed, that is satisfactory or unsatisfactory.

Analyzing the development system longitudinally, however, produces a different impression. Socially constructed design decisions affecting the speed of the application may include the functionality of the application, the way it is programmed, the amount of data involved, the characteristics of the host software, the choice of hardware, the communications network topography and configuration, the physical communications media, the network router configurations, the number of users and quantity of network traffic, and many other things. In this second analysis, the application speed is the result of a complex series of resource and design decisions - human agency rather than machine agency.

Turning this a bit further, if we focus on the development system and perform longitudinal analysis, then the characteristics of the machine look like emergent properties 
of the developers' decisions. Since none of the machine's characteristics are its own, but the result of human design decisions that are all, in principle, rescindable, a decision to award the machine agency appears an arbitrary one. It is based on the assumption that the machine's development has finished. The property, speed, of the Lotus Notes application, is a result of previous decisions about communications network configuration and hardware purchase, as well as the local decisions of the application programmers. User satisfaction as a property of system response time now appears an unwarranted type of technological determinism.

But let us examine these assumptions a bit further against the concepts identified in Tables 1 and 2. Who are the agents in this case? From a structurational context, it is a set of humans who create, install, and care for the application: the net administrators who install and keep it running, the database designers and administration staff, and the moreskilled and less-skilled user community. From the structurational cross-sectional/use perspective, we are principally concerned with the relative level of the skill-set and experience in the use of the application as possessed by any given user. If experienced and well-trained, they may get the system to do more and respond more quickly. Because of that relatively more advanced skill level, they may feel more in control and accepting of the response time behavior of the machine. The less well-trained or less experienced user is more at the mercy of the system and might be less inclined to accept the speed or response and other operational foibles.

Once we admit the whole of the longitudinal and development perspective, the human aspect of the system becomes more apparent to either the more or the less-skilled user. The system appears less arbitrary, distant, and inscrutable and hence other possible courses of action are open. One may contact the network administrator, the developers, or DBA for assistance. Or, given the particular operational setting, one may choose to accept the slowness because the given development and administrative setting is judged to be unfavorable to affecting a change. Decisions made by human actors are constrained by the structure of previous design and business decisions and are, therefore, reflected in the ways the software behaves as they help define the structural limits of the whole system.

From the actor network theory perspective, we now must look beyond the human actors and add other actants (agents) to the list. Those may include the application itself, the network, other users of the network, and those decisions and decision makers that made the commitment to using Notes (rather than other possible collaborative software tools). In an actor network theory cross-sectional view we must examine the whole of the decisions and decision contexts that brought about a network of operational events. Here the user may now consider the range of response options when they perceive response time as diminishing. Since "the machine" has a perceived agency and the interaction of the machine and other mutually dependent components (agents) is understood, the user may, at the time of use, phone up the network administrator and request a higher priority or extra privileges on the queue (override of the rule set) or a check to see it the network is down at that particular time. This may translate to a greater set of options in the hands of an actor network aware user and might, therefore, be considered when we are designing such systems. 


\subsection{Deconstruction 2: The Ubiquitous Cash Dispenser}

The second example is a thought experiment after the fashion of Introna and Whitley (1997). The content of the experiment concerns an automatic teller machine (the familiar cash dispenser).

A cash machine dispenses me money. On day one it works perfectly and with the money dispensed I am able to buy lunch for my friends. I return the next day but it is out of order. On the third day it is working, it seems, but refuses to give me money.

Cross-sectional analysis of the cash dispenser in use may yield an impression of machine agency. It certainly has an effect on my subsequent behavior. Either I can buy lunch for my friends, or they pay for themselves. It dispenses, it is unable to dispense, or it refuses to dispense-implying some form of intentionality. It makes simple decisions prescribed by its rule base. It appears largely independent and self-governing. In the structurational story, it is a resource I employ to facilitate my lunch date interactions with my friends. Of course, this theory base forbids us to ascribe it agency. In the actor network story, it is a black box actant in the lunch network that does not need to be further investigated unless it becomes a problem. It "speaks" for the bank (yes, you may have some money). However, longitudinal analysis of the development system paints a different picture. Connotations of intentionality in the machine recede. The "refusal" to dispense now seems a kind of linguistic shorthand. The autoteller has been designed to interface with the computer that records the state of my account. The bank's rule system forbids withdrawals when an account is overdrawn and the developer has programmed this rule into the software. Intentionality here resides with the programmer. However, the programmer is only articulating the bank's rule system; the programmer's only contribution is to buy into the rule system without questioning or reinterpreting it, so perhaps intentionality resides more collectively with the bank. In the development system, agency is distributed around many humans, perhaps around many development systems (the machine needs silicon chips, a VDU, the communications network to which it is connected, a secure power source, security devices, precise machine engineering, someone to restock it with money and consumables). One might ask whether, since the locus of agency does not rest with any one human (or even one development system), does it rest in the machine? This is essentially an emergent theory of machine agency: agency is the emergent property of previous design decisions. However, accounts of collective agency in social theory deal perfectly adequately with these phenomena without invoking emergent properties. The programmer builds software (action) according to his understanding of the bank's rule system (structure), thus re-enacting social practice, which replicates over time and space. Many such interactions constitute the fabric of social interaction (structuration theory). Alternatively, many actants (programmer, programming language, rule system, cathode-ray tube, power supply engineer, etc.) are enrolled with interests in common in the network of technical and social components that produces the machine (actor network theory). If the machine now denies me money because it is not working, one of those components is to blame. A mechanical component has failed, there is a software glitch, the communications lines are down, or the machine's 
armor failed to resist a vandal. Cross-sectional analysis of the use system shows me inconvenienced by the machine's apparent failure to do its job. The effect again is to make my friends pay for lunch. Analyzing the development system, however, shows something is unintentionally awry. Someone must, over the longer term, respecify an engineering process, debug the program, organize rerouting of the communications channels, or install better security.

Let us amend our thought experiment. What happens if the automated bank teller is replaced with a human teller? The human, as a knowledgeable actor, possesses agency; however, the outcomes are the same. If I am overdrawn, I still don't get any money (but perhaps I may renegotiate my overdraft limit). The human teller may make a mistake (software error), be sick (broken), or be assaulted by a bank robber (vandalized). Similar analysis is possible. There is an institutionalized rule system that is formalized by the programmer of the machine agent and taught to the human agent. In each case, the outcome is the result of the rule system rather than the agent.

Now what happens if we develop the cash dispenser with more functionality so that it resembles the human bank teller? Let us now give it a voice recognition interface, the ability to hold a rudimentary conversation and recognisz my signature, a large rule base encapsulating the bank's procedures, and a powerful inferencing engine. Let us give it the ability to assess my credit-worthiness and call up its manager for decisions it can't handle - in fact, the ability to do what the human teller can. This is a version of the Turing test: if the machine can do what the human can do, it must be attributed agency.

\section{Discussion}

Since we cannot perform theory-free analysis, the theoretical base must influence the analysis. Structuration theory emphasizes the agency of the knowledgeable human actor, whereas actor network encourages the co-equality of non-human agency. Therefore, a structurational analysis of an empirical situation will tend to produce a strong view of human agency, whereas an actor network theory analysis of the same situation will encourage the possibility of strong machine agency. Action on the basis of structurational analysis is likely to be focused on human actors, whereas action on the basis of actor network analysis may target humans and machines. However, the style and focus of analysis also play a large part in determining what theoretical stance will be taken (deriving theory from action) and how an empirical situation might be viewed (proceeding to action via theory). The first feature to be noted from the preceding examples is the relativity of the concept of machine agency. Machine agency can appear quite strong as long as the machines are taken as black-boxes and observed in use over a short period, but strong agency tends to disappear when the development system is considered historically. This is illustrated in Table 3.

Giddens' discussion of agency involves three factors: the capacity to make a difference, power, and intentionality. All three can be observed in the preceding examples. The cash dispenser clearly affects peoples' future actions-making a difference - and so exerts power. Power is related to the scale of the effect. My pen, a simple machine, may stop working but the effects on me are negligible; the cash dispenser may cause me considerable inconvenience, but failure of the brakes on my car may end 


\section{Table 2. Framework for Deconstruction of Machine Agency Examples}

\begin{tabular}{|c|c|c|c|}
\cline { 3 - 4 } \multicolumn{2}{c|}{} & \multicolumn{2}{c|}{ Focus of Analysis } \\
\hline \multirow{3}{*}{$\begin{array}{c}\text { Style of } \\
\text { Analysis }\end{array}$} & Longitudinal & Development \\
\cline { 2 - 4 } & Cross-sectional & $\begin{array}{c}\text { Strong } \\
\text { Machine } \\
\text { Agency }\end{array}$ & \\
\hline
\end{tabular}

my life. In the case of the cash dispenser, the refusal to dispense might be considered a form of intentionality, at least in one analysis. Intentionality attributed to machines has quite a strong hold on our everyday thoughts ("I braked but the car wouldn't stop," "my laptop won't connect to the network," "the central heating's playing up today"). However, some agency-related concepts are more essentially human than others. In each case, we can analyze these concepts in a different way by looking at the design system. The consequences and effects that the machine engenders will probably still seem like attributes of the machine; however, intentionality may be more likely to be seen as a property of the human designers.

The last question to be considered is the distinguishing feature of agency. What does the human teller have that the cash dispenser does not which allows it more agency? Most of us can concede that a machine can act, can demonstrate its power, and that its actions have effects and consequences. What do we have to add to the machine to allow it to be viewed as an agent in the same way as the human? Perhaps the clue is in the human's ability to respond to an overdrawn client. The cash dispenser has one response, which is programmed: no cash. The human has variety in the way (s)he handles the task and, in the last resort, the ability to override the rule systems, or operate in a wider context. To make the machine resemble the human in terms of agency, the designer must greatly enhance the variety of its responses to different circumstances and allow it to interpret the underlying rule systems with the flexibility that the human displays. It must be given independence, the ability to govern itself, decision-making powers, intentionality, and volition. These are the more human characteristics of agency, which we find it harder to ascribe to machines. We term this (rather human) side of agency autonomy.

\section{Machine Agency as Perceived Autonomy}

Now we consider underlying models of machine agency. The separation of development and use of IT immediately offers one version of machine agency: sequential "discontinuous separation of design and use" (the phrase is from Orlikowski 1992). In this 
version of technological agency, the machine is first designed, then has agency. In development, the system is in the hands of the developers, who exert agency over its components. Agency is the emergent property of the development process and becomes embedded in the completed machine. Now the machine can have an effect on the people who use it. However, this view of development and use is a particularly impoverished one. It derives from the ubiquitous project-based view of information systems development. A computerized information system is developed in a discrete block of time (project); when it is finished, it is implemented and is then in use. Analyzing formal project activities takes little account of their wider social context and history. In life cycle models, on-going development work is simply re-labeled "maintenance." No account is taken of "interpretive flexibility" (Orlikowski 1992) - the capacity of users to shape the systems with which they work. Better understandings of the relationships between development and use recognize that they are recursively and reflexively dependant upon each other. Development cannot take place without consideration of the use system; use is a form of feedback on development; machines evolve in an emerging process which is dependent on both overlapping systems. ${ }^{2}$ Jones' double mangle model incorporates this understanding. Human agents seek to "channel material agency to shape the actions of other human agents," or to "marshal material agency to direct the actions of other human agents," in a "double dance of agency." Machine agency is at the interface of the two social systems: use and development. Its distinguishing quality is autonomy. Two interlinking uses of the word autonomy may be distinguished. The first is its natural language meaning of "independent, self governing." Now we refer to sets of concepts that are related to agency, but comprise its more human side. The second, in this theoretical context, is the sense of autonomy from the machine's development system. However, this kind of autonomy is partly a function of the analyst's approach. If the analyst leaves the machine as a black box by concentrating on cross-sectional analysis of the use system, the machine is likely to exhibit more of the characteristics of autonomy: strong agency. If, however, the analyst chooses to deconstruct the black box, via longitudinal analysis of the development system, certain features of its agency are more likely to be attributed to its human designers. Therefore, we find that autonomy in the machine is not integral to the machine itself, but strongly dependent on the way it is perceived.

This relative concept of machine agency as perceived autonomy is consistent both with structuration theory and actor network theory. In structuration theory, Giddens theorizes social systems as integrated routinized practices, in the recursive cycle of structure and agency, connected by time-space edges. All of these concepts can be applied to the analysis of the social systems of use and design. When an analyst perceives autonomy in a machine, (s)he perceives the temporary, embedded, emergent outcome of the development system. Development and use can also be analyzed as actor networks. In the use network, the machine is a black box; the deconstruction of the black box is its development network.

\footnotetext{
${ }^{2}$ When I write to my bank complaining about the charging system for cash dispensers (for which I am normally part of the use system), I deliberately attempt to locate myself in the machine's development system.
} 


\section{Conclusions}

Understanding the relationship between the social and the technical, the human and the machine, is at the heart of the study of information systems - an applied discipline in which action is related to theory via analysis. The recent theoretical debate revolving around actor network theory and structuration theory highlights the fundamental incompatibility of these two theoretical positions regarding the question of non-human agency. In actor network theory, non-humans and humans alike are afforded symmetrical agency, whereas in structuration theory only humans can be agents. Jones' double mangle model tries to resolve this difficulty by offering non-humans limited agency. Jones adopts a compromise approach in which he seeks to amend the theory base to solve the problem. He sees the inherent contradiction and incompatibility of the two theoretical accounts of machine agency, and tries to create a theoretical solution that will help explain IS phenomena. Whatever its theoretical merits, this model presents difficulties for researchers who want to do practical things in IS. It is wholly compatible neither with structuration theory or actor network theory, nor does it offers similarly well-elucidated concepts. As such, it weakens the analytical power of the researcher, and hence the capacity of the actor to take action. It leaves the would-be analyst and practitioner in a position that is essentially inactionable, while abandoning the relative security offered by the structuration and actor network frameworks.

Our deconstructions allow us to understand that the starting theory base, and the style and focus of analysis, inevitably influences, and to some extent governs, how we perceive the agency of a machine in any empirical situation. Our perception is relative, depending on whether we choose to take the machine as given (black box) or deconstruct its development. Agency is a complicated association of concepts, not a crystal-clear dictionary definition, and we find it harder to ascribe some of these concepts to machines than others. ${ }^{3}$ For instance, people can generally cope with the idea that machines act, and their actions have consequences, but find it harder to attribute to them our more human characteristics such as intention or volition. We develop the concept of autonomy to refer to these human elements: self-government, independence, intentionality, volition, and decision making. When we perceive the more human aspects of agency in the machine, we perceive the machine as more autonomous. That perception deserves to be taken seriously by developers and managers of IT infrastructures, despite the fact that it may change if we study the historical development of the machine in more depth. Restated more simply, the closer one is to the moment, and to the situation of use (a user faces a machine that does not respond to their will), the more likely one is to attribute autonomy to the machine. A more formal description (inspired by Latour) is: every black box (IT system) is a network waiting to be deconstructed. Nevertheless, there may be numerous instances when we either choose not to open, or where we believe we are constrained from opening, the black box.

Our analytical devices and deconstructions lead us toward a rethinking of machine agency: machine agency as perceived autonomy. This conceptualization is compatible with both structuration theory and actor network theory and, therefore, leaves the would-

\footnotetext{
${ }^{3}$ The personification of inanimate objects has been the study of cultural anthropologists and art historians (c.f. Langer 1953; Skillman 1981; Turkle 1984).
} 
be analyst/actor in a stronger, not a weaker, position. In undertaking analysis that leads to useful action we need to have our cake and eat it. Focusing on the development story exposes the roles of the human agents who make information systems and encourages a socially determinist view. Focusing on the information systems in use ignores the story of the machines' construction and encourages a technologically determinist interpretation: now we mainly look at the finished machine as it constrains and enables social interactions. The trick is to have both stories in mind at the same time. What this buys the analyst is a way to imagine and anticipate user response to systems under design. What it buys the users is a way to understand the underlying conceptualization of the system.

This approach differs substantially from our initial point of reference, Jones' double mangle model. Jones tries to resolve incompatibilities between actor network theory and structuration theory at the cost of inconsistency with both theories. We offer instead a position that is consistent with both actor network theory and structuration theory. Rather than accepting or denying machine agency, we allow that machines may have a perceived autonomy. Perceived autonomy is a property derived partly from what people think the machine has and does and partly from what is designed into the machine. When we distinguish between analysis styles - both cross sectional and longitudinal - and the use system versus the development system, we acknowledge contexts that can never really be wholly separate. We offer a way to keep the questions of design and use in constant play; that is, to forestall the freezing of the conception of a given system while remembering that specific properties of a machine are never fixed but are always emerging (Truex, Baskerville, and Klein 1999). What we give designers and users, therefore, is a way to keep both arguments in focus at the same time while drawing upon two well understood bodies of theory and of practice. What should the developer, manager, or user of an information system do with these insights? The trick becomes living with the anomalies and remaining in the difficult dialectical center, rather than trying to resolve one problem at the expense of impoverishing the wider analytical repertoire. We should use the analytical power of the competing frames of reference to keep the different perspectives, of machine agency in focus at the same time. If notions of agency depend upon theoretical and analytical perspectives we do not suggest ironing them out to arrive at the "correct" theoretical stance; rather, we harness the power of their dialectical tensions in order to arrive at richer understandings. Both actor network theory and structuration theory are different routes to those understandings. The recursive emergent nature of development and of use should be both recognized and exploited.

\section{References}

Barley, S. R. "Technology as an Occasion for Structuring: Evidence from Observation of CT Scanners," Administrative Science Quarterly (31), 1986, pp 78-108.

Beath, C. M., and Orlikowski, W. J. "The Contradictory Structure of Systems Development Methodologies: Deconstructing the IS-User Relationship in Information Engineering," Information Systems Research (5:4), 1994, pp 350-377.

Boje, D. M., and Dennehy, R. F. Managing in the Postmodern World: America's Revolution Against Exploitation. Dubuque, IA: Kendall /Hunt Publishing Co., 1994. 
Brooks, L. "Structuration Theory and New Technology: Analyzing Organizationally Situated Computer-aided Design," Information Systems Journal (7), 1997, pp 133-151.

Checkland, P. B., and Scholes, J. SSM in Action. New York: Plenum, 1990.

Derrida, J. (ed.). Différance. Margins of Philosophy. Chicago: University of Chicago Press, 1982.

Franz, C. R., and Robey, D. "Strategies for Research on IS in Organizations: A Critical Analysis of Research Purpose and Time Frame," in Critical Issues in Information Systems Research, R. J. Boland and R. Hirschheim (eds.). Chichester, UK: Wiley, 1987.

Giddens, A. The Constitution of Society. Cambridge, UK: Polity Press, 1984.

Hopper, P. “Emergent Grammar," Berkeley Linguistics Society (13), 1987, pp. 139-157.

Introna, L. D., and Whitley, E. A. "Imagine: Thought Experiments in Information Systems Research," in Information Systems and Qualitative Research, A. S. Lee, J. Liebenau, and J. I. DeGross (eds.). London: Chapman and Hall, 1997.

Jones, M. "Structuration and IS," in Rethinking Management Information Systems, W. L. Currie and R. D. Galliers (eds.). Oxford: Oxford University Press, 1997.

Jones, M. "Information Systems and the Double Mangle," in Information Systems: Current Issues and Future Changes, T. J. Larsen, L. Levine, and J. I. DeGross (eds.). Laxenburg, Austria: IFIP, 1999.

Jones, M., and Nandhakumar, J. "Structured Development? A Structurational Analysis of the Development of an Executive Information System," in Human, Organizational and Social Dimensions of Information System Development, D. E. Avison, J. E. Kendall, and J. I. DeGross (eds.). Amsterdam: North-Holland, 1993.

Langer, S. K. An Introduction to Symbolic Logic. New York: Dover Publications Inc., 1953.

Latour, B. Nous n'avons jamais été modernes. Paris: Editions La Découverte, 1991.

Latour, B. Science in Action. Cambridge, MA: Harvard University Press, 1992.

Latour, B. "Social Theory and the Study of Computerized Work Sites," Information Systems Research, Special Issue, "IT and the Structuring of Organizations," W. J. Orlikowski and D. Robey (eds.), (2:2), 1996, pp 143-169

Markus, M. L., and Robey, D. "Information Technology and Organizational Change: Causal Structure in Theory and Research," Management Science (24:5), 1988, pp 583-598.

Orlikowski, W. J. "The Duality of Technology: Rethinking the Concept of Technology in Organizations," Organization Science (3:3), 1992, 3, pp 398-429.

Orlikowski, W. J., and Robey, D. (eds.). "IT and the Structuring of Organizations," Special Issue, Information Systems Research (2:2), 1991, pp 143-169.

Skillman, Y. "Ancient Inspirations and Contempory Intepretations," Roberson Museum Exhibition Series, D. Truex (ed.). Binghamton, NY: Roberson Memorial Inc., 1981, pp. 5; 152.

Truex, D. P., Baskerville, R., and Travis D. "Amethodical Systems Development: The Deferred Meaning of Systems Development Methods," Accounting Management and Information Technology (9), forthcoming, pp 1-27

Truex, D., Baskerville, R., and Klein, H. "Growing Systems in Emergent Organizations," Communications of the ACM (42:8), 1999, pp 117-123.

Turkle, S. The Second Self. New York: Macmillan, 1984.

Walsham, G. Interpreting Information Systems. Chichester, UK: Wiley, 1993.

Walsham, G. "Actor-Network Theory and IS Research: Current Status and Future Prospects," in Information Systems and Qualitative Research, A. S. Lee, J. Liebenau, and J. I. DeGross (eds.). London: Chapman \& Hall, 1997. 


\section{About the Authors}

Jeremy Rose won an exhibition to read English at Cambridge and subsequently trained to be a musician at the Royal College of Music in London. After working for some years for the Rambert Dance Company and Music Projects London, he retrained at Lancaster, gaining his MSc in Information Management with distinction. As a senior lecturer in Business Information Technology in the Faculty of Management and Business at the Manchester Metropolitan University, he collaborated with Peter Checkland on research projects. More recently he has been working with colleagues at the University of Aaalborg. While completing his Ph.D. at Lancaster, he has published in management, systems and IS forums. His research interests include IS development and evaluation, systems methodology, structuration theory, actor network theory, BPR and knowledge management, the health service, and inter/intranet development. Jeremy can be reached by e-mail at J.Rose@mmu.ac.uk.

Duane Truex is an assistant professor of Computer Information Systems at Georgia State University and a Leverhulme Fellow at the University of Salford, England. His first degrees were in the arts and he spent his early professional life in symphony orchestra and museum management. As a critical social theorist, his work in information systems research has been generally concerned with emancipatory issues of information technologies. He also writes about information systems development and IS research methods. He has published in Communications of the ACM, Accounting Management and Information Technologies, Information Systems Journal, IEEE Transactions on Engineering Management, the IFIP transactions series, and in various other proceedings. Duane can be reached at dtruex@gus.edu. 